\title{
Desinstitucionalização da Assistência Psiquiátrica: Uma Perspectiva Crítica
}

MAURICIO LOUGON*

O propósito deste artigo é tecer algumas considerações críticas a respeito do processo de mudança instaurado em hospitais psiquiátricos públicos do Rio de Janeiro nos anos 80 , voltado para a desinstitucionalização da assistência. Utilizarei como estudo de caso a experiência de mudança institucional ocorrida na Colônia Juliano Moreira, no Rio de Janeiro, recorrendo para isto ao material contido em um estudo por mim realizado anteriormente. ${ }^{1}$

Minha análise irá focalizar, também, as influências exercidas nesse processo pelo movimento conhecido como "psiquiatria democrática italiana", discutindo algumas dimensões de seu modelo teórico e a sua apropriação em nosso meio. Parto do discurso dos protagonistas dessa experiência — os titulares da instituição — buscando analisá-lo em suas dimensões essenciais:

"No Brasil, a Colônia Juliano Moreira (CJM) é o asilo típico, fruto do modelo de exclusão social. Buscando encontrar uma solução para os seus 2.600 pacientes, a nova política assistencial da CJM se compromete com uma proposta de modificação do espaço

* Psiquiatra, mestre em Antropologia Social pelo Museu Nacional/UFRJ e pesquisador do NUPES/ENSP/Fiocruz.

1 M. Lougon. Os Caminhos da Mudança: Alienados. Alienistas e a Desinstitucionalização da Assistência Psiquiátrica Pública, Tese de Mestrado em Antropologia Social. PPGAS/Museu Nacional/UFRJ, 1987. 
asilar através de um trabalho alternativo que procura humanizar e democratizar a instituição. "2

Este fragmento de um texto institucional de caráter programático, produzido por um dos principais mentores do projeto de mudança, me parece bastante típico e adequado para situar os principais elementos que o constituem. Portanto, tratarei de analisá-lo termo a termo, tomando-o como uma pista inicial e tentando identificar em que realmente se constitui essa mudança, a forma como é vista e proposta por seus protagonistas.

Nesta perspectiva, o hospital, tal como se encontrava previamente, ou como algo que deverá ser transformado, é descrito como um "asilo típico, fruto do modelo de exclusão social", primeiro elemento de nossa análise; os atores, por seu lado, propõem-se a realizar uma "modificação do espaço asilar [procurando] humanizar e democratizar a instituição", proposta que se constituirá no segundo alvo de nossa atenção, juntamente com o instrumento proposto para realizar a mudança, que é apresentado como "trabalho alternativo".

\section{A crítica ao modelo asilar}

O asilo típico, fruto do modelo de exclusão social, pode ser entendido aqui como incluído no conceito de instituição total proposto por Goffman. ${ }^{3}$ O modelo de exclusão social refere-se ao isolamento de indivíduos de conduta desviante ou considerados indesejáveis pela comunidade. Corresponde ao padrão descrito por Lévi-Strauss como típico das "culturas antropoêmicas" — que, figuradamente, "vomitam" seus desviantes —, em oposição às culturas antropofágicas, aquelas que os absorvem. ${ }^{4}$ Essa concepção de asilo,

2 Ministério da Saúde, Política Assistencial da CJM para 1982, Rio de Janeiro, Colônia Juliano Moreira, 1982, mimeo (grifos meus). A Colônia Juliano Moreira passará a ser referida eventualmente, por comodidade, como CJM.

3 Para este autor "Uma instituição total pode ser definida como o lugar de residência e trabalho em que grande número de indivíduos que se acham na mesma situação, separados da sociedade mais ampla por considerável período de tempo, leva uma vida fechada e formalmente administrada. As prisões servem como exemplo disso claramente, desde que consideremos que o aspecto característico de prisões pode ser encontrado em instituiçōes cujos participantes não se comportam de forma ilegal". E. Goffman, Manicômios, Prisões e Conventos, São Paulo, Perspectiva, 1974 , p. 11.

4 Cf. C. Lévi-Strauss, Tristes Trópicos, São Paulo, Anhembi, 1956. 
expressa no discurso institucional focalizado, corresponde, ainda, a uma abordagem de hospital psiquiátrico com maior ênfase em um de seus atributos. Conforme Levinson, representante do sócio-funcionalismo americano - aqui citado apenas com a finalidade de uma demarcação contrastante, com o pensamento psiquiátrico que subjaz à proposta de mudança no processo estudado - , essas instituições atendem fundamentalmente a três finalidades: "Devem induzir a mudanças psicológicas nos pacientes (terapêutica), satisfazer suas numerosas necessidades bio-psicossociais (atenção) e mantê-los legalmente confinados até que sejam considerados sãos para retornarem à vida civil (reclusão)".

No discurso institucional analisado, o hospital aparece identificado, mais freqüentemente, com a terceira finalidade descrita e, também, como instrumento de controle social, aspecto este que tratarei mais adiante.

A proposta de modificação do espaço asilar implica um processo de transformação do hospital, até o momento caracterizado como asilo típico. Esse processo constitui, ele mesmo, um nódulo de importância central no presente artigo e necessita de uma explicação mais detalhada, pois que tratarei de incluí-lo em um movimento mais abrangente, que será definido como desinstitucionalização da assistência médico-psiquiátrica aos assim chamados doentes mentais.

A proposta de transformação do hospital; como aparece nos textos que propõem mudanças na CJM, parte do questionamento de sua legitimidade ética, eficácia técnica e significado político enquanto intervenção "terapêutica" na sociedade. Assim, parece oportuno delinear o contexto mais geral no qual aparece essa contestação específica da CJM enquanto asilo tradicional.

A crítica da instituição psiquiátrica como fenômeno geral não é fato recente: ora se volta para os recursos terapêuticos disponíveis, ora para os resultados obtidos, ora ainda para os aspectos éticos ou humanitários envol-

5 D. J. Levinson e C. B. Gallagher, Sociologia del Enfermo Mental, Buenos Aires, Amorrortu, 1971.

6 "Contudo, por desinstitucionalização, como todos os rótulos, tem-se as mais diversas versões e sob esta denominação podemos assistir neste momento uma série de experiências, que vão desde medidas administrativas e técnicas visando à constituiçāo de serviços comunitários até abordagens radicais onde a produção de enfermidade mental é questionada de modo mais dramático". Cf. A. M. Pitta-Hoisel, Sobre uma Política de Saúde Mental, Tese de Mestrado em Medicina Preventiva, Universidade de São Paulo, 1984, p. 3. 
vidos. Já em fins do século passado, no Brasil, Teixeira Brandão criticava as condições de atendimento psiquiátrico no Hospital Pedro II, onde a cura pouco ocorria.

Há um certo consenso entre os autores que tratam do desenvolvimento histórico de alternativas ao modelo asilar, quando situam o período do pósguerra como um momento em que os questionamentos se avolumaram, determinando mudanças concretas e amplas.

Entre as razões do desenvolvimento de alternativas ao modelo asilar existem alguns fatores que, embora atuando independentemente, não-relacionados entre si, têm em comum o período em que ocorreram - os anos 40 e 50 - e o fato de propiciarem transformações no modelo de assistência psiquiátrica, ou pelo menos apontarem a necessidade delas. Dentre esses fatores poderíamos assinalar o clima de "liberalismo" e "democracia" reinante após a vitória dos aliados contra o totalitarismo nazi-fascista, incompatível com as características autoritárias do asilo tradicional; criação de movimentos pró-direitos civis, associações de parentes e amigos dos doentes mentais, clamando por seus direitos; análises provenientes das Ciências Sociais que apontavam para as características repressoras e autoritárias da instituição psiquiátrica tradicional; e, finalmente, no início dos anos 50, o surgimento dos neurolépticos, que irão facilitar o tratamento extra-hospitalar.

Dando continuidade a esse movimento, os anos 60 assistiram ao aparecimento de uma série de questionamentos à instituição psiquiátrica, alguns mais radicais, contestando a legitimidade dos próprios objetivos e saberes da especialidade, outros menos, originados em seu próprio interior, visando recuperá-la ou modernizá-la.

Apesar de consideráveis diferenças entre si, essas reflexões, surgidas no interior da própria psiquiatria ou das Ciências Sociais, têm em comum a crítica aos efeitos prejudiciais acarretados pela permanência prolongada em

7 Cf. P. D. C. Amarante. Psiquiatria Social e Colônia de Alienados no Brasil (1830-1920). Tese de Mestrado. Instituto de Medicina Social/UERJ, 1982.

8 Para uma abordagem mais sistemática desse desenvolvimento histórico ver, sobretudo sobre o caso americano, R. Castel, A Gestâo dos Riscos. Rio de Janeiro. Francisco Alves, 1987 e R. Castel et alli. The Psychiatric Society, Nova Iorque. Columbia University Press. 1982. Entre nós, ver A. T. A. Venâncio, Sobre a Nova Psiquiatria no Brasil. Tese de Mestrado em Antropologia Social, PPGAS/Museu Nacional/UFRJ, 1990: J. J. Sampaio, Hospital Psiquiátrico Público no Brasil: A Sobrevivência do Asilo e Outros Destinos Possíveis, Tese de Mestrado. Instituto de Medicina Social/UERJ, 1988; e A. M. Pitta-Hoisel. Sobre uma Política.... op. cit. 
estabelecimentos psiquiátricos. Os pontos fundamentais dessas críticas ao modelo assistencial baseado na hospitalização podem ser assim sumariados: o caráter segregador que conduz ao isolamento; dependência crescente e conseqüências da "síndrome do hospitalismo"; agravamento ou cronificação da doença pela permanência no hospital; características desumanas, "despersonalizantes" da instituição; e o estigma gerado pela estadia em um hospital psiquiátrico. ${ }^{9}$

Um grupo que se tornou muito conhecido por enfatizar esses aspectos é o que denominamos, lato sensu, o dos "antipsiquiatras", no qual poderíamos incluir, juntos. e apenas no contexto a que nos referimos (da desinstitucionalização), Laing, Cooper, Esterson e Basaglia, que elaboram algo como uma rationale de contestação ao hospital psiquiátrico tradicional bastante alicerçados no trabalho de Goffman. ${ }^{10}$

No caso analisado, da CJM, acredito poder identificar nos textos dos projetos, documentos e nas falas dos técnicos que propõem a transformação, uma certa "ideologia psiquiátrica" influenciada sobretudo por Basaglia, mais que pelos outros autores aqui citados. Sua abordagem da doença mental como um tema fundamentalmente político, parece ter sido muito importante para as formulações da questão feitas pelos protagonistas do processo de mudança estudado.

Os fatores históricos já mencionados, entre outros, conduziram a mudanças substanciais na orientação da prestação de serviços de saúde mental em diversos países. Fundamentalmente, essas mudanças representaram um deslocamento da base do modelo assistencial, o hospital psiquiátrico, para a comunidade, apoiado em recursos extra-hospitalares em uma tentativa de desospitalização da assistência.

Dentre os países onde esse processo de transformação ocorreu, os EUA constituem um caso onde a mudança se instaurou há mais tempo e está mais

9 Uma cuidadosa análise crítica da hipótese de Barton sobre os mecanismos institucionais de cronificação tendo como referência a Colônia Juliano Moreira pode ser vista em P. G. G. Delgado, "Determinantes Institucionais de Cronificação". Jornal Brasileiro de Psiquiatria, vol. 40. $n^{\circ} 3$, abril de 1991 .

10 Estamos nos referindo, entre outros, aos seguintes textos que nos parecem representativos dessa contestação: R. D. Laing e A. Esterson. Sanity, Madness and the Family. Londres. Penguim Books, 1970; D. Cooper. Psiquiatria e Antipsiquiatria, Sāo Paulo, Perspectiva, 1973: F. Basaglia. La Institución Negada: Informe de un Hospital Psiquiátrico. Buenos Aires, Barral. 1972: e E. Goffman, Manicômios, Prisōes.... op. cit. 
fartamente documentada e analisada na literatura disponível, razão por que recorrerei a ela.

A categoria que se nos apresenta como mais abrangente para incluir os aspectos do processo aludido, de desospitalização, é talvez a de desinstitucionalização da assistência. Para defini-la, podemos nos servir dos indicadores fornecidos pelo diretor do Instituto Nacional de Saúde Mental dos EUA, que incluem:

“1. a prevenção de internaçōes inadequadas em instituições psiquiátricas, procurando alternativas comunitárias para o seu tratamento;

2. o retorno para a comunidade de todos os pacientes institucionalizados que tiveram preparo adequado para tal mudança;

3. o estabelecimento e manutenção de sistemas de suporte comunitário para as pessoas não-institucionalizadas que estejam recebendo serviços de saúde mental na comunidade. $" 11$

Como já apontei, sob o conceito de desinstitucionalização encontram-se diferentes experiências históricas, em diferentes países, às quais subjazem concepções teóricas distintas. O uso diferencial desse conceito aparece bem explicitado na comparação entre as experiências italiana e americana. Neste sentido, Roțteli afirma que:

"Chamávamos o modelo que levamos a efeito em Trieste de desinstitucionalização, ou seja, um modelo de desconstrução lenta e gradual de todos os preceitos dos hospitais psiquiátricos e de construção, fora do mesmo, de novos serviços que tivessem uma lógica inversa à da exclusão do internamento, da opressão própria dos hospitais psiquiátricos.

Infelizmente, nos Estados Unidos, por exemplo, a palavra desinstitucionalização transformou-se numa caricatura disso, ou seja, acabou significando uma 'desospitalização', o fechamento dos hospitais, um atirar as pessoas na rua". 12

Para contextualizar esse processo em sua dimensão numérica, verificase nos EUA uma substancial diminuição no número de pacientes hospitalizados por longo período - de cerca de 559 mil, em 1955, para cerca de 193 mil, em 1975, o que representa uma redução de aproximadamente $65 \%$-, contrariando as expectativas de aumento dessa população de internos, que certamente ocorreria, acompanhando o crescimento vegetativo da população em geral, caso não houvesse mudança na política de saúde mental. Entretan-

11 B. S. Brown, Deinstitutionalization and Comunity Support Systems - Statement by the Director, Estados Unidos, National Institute of Mental Health, 1975.

12 F. Rotteli, mesa-redonda no Encontro Italo-Brasileiro em Saúde, Salvador, junho de 1989. 
to, o número total de pacientes psiquiátricos não se reduziu; eles foram transferidos para centros de saúde mental e instituições similares. ${ }^{13}$

Tentando analisar esse mesmo processo no nosso meio, em que pese a existência de reformulações na assistência proposta desde a unificação dos IAPs no INPS, em 1966, a mudança do modelo assistencial psiquiátrico no sentido dé que tratamos da desinstitucionalização é fato muito recente. Uma indicação do descompasso entre a política de desinstitucionalização nos EUA e no Brasil pode ser verificada no estudo epidemiológico de Lucia Abelha Lima, ${ }^{14}$ que apresenta os anos de 1974/75 como o período em que a população de pacientes internos na CJM atingiu o seu número máximo. A mesma autora aponta como um dos fatores para a redução posterior desse número, em meados dos anos 70, a transferência dos pacientes para instituições asilares privadas similares, caracterizando uma política de privatização no setor e de transinstitucionalização mais do que desinstitucionalização.

No documento Manual de Serviços de Assistência Psiquiátrica,${ }^{15}$ por exemplo, são preconizados, sob a influência preventivista, alguns princípios da desinstitucionalização, tais como a redução de internações e a criação de recursos alternativos ao hospital. Entretanto, como aponta Resende, "que se saiba o Manual de Serviços jamais foi efetivamente implementado pelo INPS". ${ }^{16}$ O Plano de Reorientação da Assistência Psiquiátrica ao Nível Previdenciário, elaborado pelo CONASP em 1982, propõe pela primeira vez a instrumentação da mudança da política de saúde mental no sentido da desinstitucionalização da assistência, sugerindo:

"[evitar] Internações desnecessárias motivadas pelos fatores de distorções próprias à forma de remuneração por produção [...] A assistência em Saúde Mental deve [...] ser predominantemente extra-hospitalar." 17

13 Cf. E. L. Bassuk e S. Gerson, "Deinstitutionalization and Mental Health Services", Scientific American, vol. 238, nº 2, fevereiro de 1978, pp. 46-53.

14 L. A. Lima, O Estigma do Abandono: Estudo Epidemiológico de uma População de Crianças e Adolescentes Internadas na Colônia Juliano Moreira, Vindos Diretamente da Funabem, Tese de Mestrado, Programa de Pós-Graduação em Saúde Pública, ENSP/Fiocruz, 1993.

15 INPS, Manual de Serviços de Assistência Psiquiátrica, INPS, 1973.

16 H. Resende, "Política de Saúde Mental no Brasil: Uma Visão Histórica", in A. Tundis e Costa, orgs., Cidadania e Loucura, Petrópolis, Vozes, 1987.

17 Brasil. Programa de Reorientaçāo da Assistência Psiquiátrica Previdenciária, Ministério da Previdência e Assistência Social-CONASP, 1982. 
Observa-se que a instituição psiquiátrica, construindo a categoria médica do doente mental a partir do louco não medicalizado (que se confundia com mendigos, criminosos, prostitutas etc.), avocou a si os encargos de custódia, mais que assistenciais, desses doentes, isolando-os da comunidade com a intenção de proteger a ambos. Agora, a mesma instituição devolve o louco que outrora seqüestrou do convívio social, propondo que a comunidade redefina suas representações a respeito desse paciente psiquiátrico e o acolha.

\section{Estratégia e atitudes na práxis de mudança}

Além dos pressupostos teórico-ideológicos que inspiraram a transformação mencionada, houve atitudes de cunho prático no âmbito técnico-administrativo que, em seu conjunto, marcaram a face exposta (extinção de eletroconvulsoterapia, desativação dos quartos-fortes e fechamento para novas internações), freqüentemente apresentada para caracterizar o processo, como que sua reificação. Nesse sentido, tomando por base a estratégia adotada para promover a mudança, podemos utilizar Majastre para identificar duas atitudes possíveis para a transformação do hospital psiquiátrico, que o autor chama tecnocrática e comunitária, as quais, acredito, são pertinentes ao caso estudado:

"A primeira atitude é aquela que poderíamos chamar de 'tecnocrática'. A mudança aparece como a substituição da ordem antiga por uma ordem nova; esta nova ordem é determinada, desejada pelo médico-chefe ou pelo coletivo de médicos. Fundamentandose sobre exigências racionais, técnicas. a instância médica combate as estruturas anteriores, impōe o que ela supõe ser bom para os doentes. As atitudes de oposição não são analisadas como oposição à pessoa ou ao desejo do médico, mas como oposição à mudança, má vontade, conservadorismo". 18

A atitude de conduzir a mudança a partir da certeza de sua adequação política aparece bem marcada no material coletado, embora os técnicos protagonistas do processo raramente a assumissem de forma explícita, adotando em seu discurso público a atitude comunitária da qual tratarei posteriormente.

18 J. O. Majastre, L'Introduction du Changement dans un Hôpital Psychiatrique Publique. Paris, Maspero, 1972, p. 78. 
Um dos primeiros indícios de que a mudança ocorreria, apareceu em meados de 1980, sob a forma de denúncias contra a precariedade das condições de vida e da assistência dada aos internos, veiculadas nos jornais e na televisão, pressionando o Ministério da Saúde a investir na transformação. As medidas que se seguiram foram decididas e colocadas em prática pelo diretor da CJM e por um pequeno grupo de médicos que o assessorava de forma direta. Respaldavam-se, mais que em um consenso, na certeza política de sua adequação e no poder da instância médica para garantir sua execução por meio de uma ordem de serviço.

A suspensão dos tratamentos com eletrochoque, extensiva aos 2.600 pacientes, foi a primeira delas - a eletroconvulsoterapia era indicada e aplicada com certa liberalidade em períodos anteriores, como registram os prontuários dos pacientes. Esse tipo de tratamento, bastante temido pelos internos, além da assim chamada indicação médica, tinha também uso disciplinar, podendo ser aplicado naqueles que transgrediam as regras de conduta.

Outra decisão de impacto, no sentido de demonstrar de forma cabal a mudança para uma nova ordem, consistiu na abertura dos "quartos-fortes". Cada hospital dispunha de um conjunto de celas individuais dotadas de um catre, uma latrina de cimento e fechadas por uma porta gradeada de ferro ou madeira espessa. A abertura dos quartos-fortes constituiu um momento importante, de grande significado simbólico para o processo de mudança, marcando uma fronteira entre a "colônia velha", autoritária e fechada, e a "colônia nova", democrática e aberta.

Este fato dividiu as opiniões da equipe de funcionários (escolaridade elementar e média) e técnicos (nível superior): alguns, sobretudo os primeiros, se mostraram temerosos, inconformados com a idéia, considerando mesmo que ela poderia acabar em tragédia; outros, francamente favoráveis à medida, lamentavam que não tivesse sido tomada há mais tempo. As reações contrárias vieram principalmente dos enfermeiros, guardas e vigilantes, que perceberam estar perdendo um dos principais meios de controle sobre os internos.

Como uma janéla aberta para a vida institucional, tais acontecimentos permitem observar como os integrantes desse processo agiam e expressavam suas opiniões sobre a "mudança". Alianças foram criadas, grupos formados a partir de iđentificações quanto a posições assumidas, gerando, ao mesmo tempo, oposição entre seus segmentos. O grupo dos técnicos como um todo aprovava e promovia as novas medidas, opondo-se ao dos funcionários, que resistia a elas. Todavia, no interior dos grupos havia divergências e conflitos. 
Este confronto era visto pelos atores envolvidos como de ordem "políticoideológica". sendo definidos como "de direita" ou "reacionários" aqueles que menos se identificavam com algumas medidas postas em prática pela instância médica, ẹmbora aprovassem a mudança em seus termos mais gerais.

A diluição das identidades profissionais dos psiquiatras, dos psicólogos, assistentes sociais e terapeutas ocupacionais em uma única categoria de "técnicos" de saúde mental — um processo que Castel chama de desprofissionalização — foi uma das medidas tomadas pela instância médica que gerou reações contrárias, definidas como "de direita" pelos que iriam implementar a mudança.

O impacto causado pela dinâmica das relações entre indivíduos e grupos põe em relevo diferentes conflitos. expondo aspectos da vida institucional que, em outros momentos, ficaram menos aparentes, encobertos pela estrutura mais rígida de relações formalizadas entre papéis, deveres e expectativas definidos normativamente.

A repercussão dessas duas medidas - a suspensão dos eletrochoques e a desativação dos quartos-fortes - foi bastante intensa sobre os integrantes da CJM, talveż por seu cunho prático, que as tornaram mais evidentes que outras posteriores.

Uma terceira medida decidida pela direção toi a de fechar as portas do hospital para novas internações. Menos sensacional que as anteriores. raramente apareceu em depoimentos identificada como um elemento importante da mudança. Entretanto, constituiu uma estratégia para a extinção da CJM enquanto modelo asilar de assistência, limitando sua existência futura ao período de vida dos internos que lá se encontram.

Uma segunda atitude possível para empreender a transformação é a que pode ser chamada de abordagem "comunitária". Sua dimensão central consiste na negação das diferenças: as fronteiras hierárquicas e socioeconômicas de saber e poder são minimizadas para afirmar-se a participação igual de todos na comunidade em que o hospital se converte. Aqui o artífice da mudança não é o indivíduo, uma vez que este é diluído no coletivo composto por todos os integrantes do hospital. que se torna o grande responsável pela reforma. Como assinala Majastre: "Na abordagem comunitária, as diferenças, as barreiras entre os diversos grupos que compõem o hospital tendem a

19 R. Castel et alli, The Psychiatric Society.... op. cir., p. 301. 
ser negadas pela participação de todos na comunidade, que se apresenta então [...] 'como um grande corpo místico'.,"20

No caso que procuro descrever, essa atitude aparece de forma explícita e de modo bastante uniforme no discurso dos atores desde o início do processo, tanto nos documentos institucionais como nas observações feitas em reuniões e assembléias, ou ainda em depoimentos escritos e entrevistas informais. Parece corresponder à atitude assumida "oficialmente" pelos protagonistas da mudança, no sentido de ser a estratégia apresentada e defendida em todas as esferas, interna e externa, para promover a transformação.

No âmbito da comunidade intra-hospitalar, a criação de espaços coletivos de debates e discussões, mediante reuniões em todos os níveis, poderia, naturalmente, gerar também um espaço para as interações dos indivíduos, no qual apareceriam as diferenças. Em vez disso, o que ocorria era a identificação de todos em torno da mudança, denominador comum que retirava a importância de quaisquer divergências.

Aparentemente, a expressão "técnico" atende a duas finalidades: de encobrimento de diferenças nas relações entre os profissionais de nível superior e destes com os de nível médio.

No primeiro caso, ela possibilita escamotear as desigualdades de poder, de status, entre as diversas especialidades profissionais. Assim, o médico não é "mais" que a psicóloga ou a assistente social, porque são todos "técnicos" de saúde mental. A hierarquia, as disparidades de papéis com todas as suas atribuições seguem existindo de fato, mas são atenuadas e negadas no plano do discurso, dentro da perspectiva "comunitária" de transformação.

A especificidade de cada especialidade profissional diminuiu ou mesmo desapareceu, cedendo lugar à identidade mais abrangente do "técnico". Os setores que reuniam os profissionais de cada área foram extintos, sob o argumento de que as atribuições eram muito semelhantes para todos no trabalho de transformação do asilo e de ressocialização dos crônicos. Uma ou outra pessoa denunciava o "poder médico" que decidia sobre aquela extinção, algo como se, embora na qualidade de técnicos todos fossem iguais, os médicos fossem mais iguais que os outros.

20 J. O. Majastre, L'Introduction du Changement..., op. cit., p. 79. 
A questão que se colocava era a de afirmar a identidade profissional e, com ela, o indivíduo, ou negá-la, atenuá-la, ocultar as diferenças para afirmar o espirit de corps, a comunidade de iguais, a communitas.

No segundo caso, entretanto, no confronto dos servidores de nível médio e elementar com os de nível superior, as barreiras a serem transpostas eram bem maiores. Aqui, para efetivar a transformação a partir de uma perspectiva comunitária, as diferenças a serem negadas eram de outra ordem: a relação "superior" versus "subalterno" constituía-se em uma fronteira hierárquica muito marcada; e o embate teoria versus prática.

A realização de reuniões em todas as instâncias e o fortalecimento dos espaços coletivos eram estratégias centrais para a transformação do asilo, como um eixo a perpassar todo o processo. Entretanto, isso ocorria mais no plano de uma rationale concebida pelos mentores da proposta - os técnicos — e não muito compartilhada pelos funcionários.

Assim, recorrentemente, as reuniões eram vistas por funcionários como um momento ocioso que rompia a rotina diária das atividades, opondo-se a esta, como algo que tomava o tempo que deveria ser destinado ao trabalho com os pacientes. A própria representação do que seja "trabalho com os pacientes" registra diferenças importantes entre informantes dos grupos de funcionários e de técnicos:

Técnicos - "Tratar" é visto ou expresso como algo mais abstrato: dar a voz, devolver a cidadania, levar ao crescimento pessoal, devolver a liberdade, desenvolver a consciência dos direitos do paciente e sua percepção estética.

Funcionários - "Tratar" é visto ou expresso em termos mais concretos: dar remédio, dar banho, cortar cabelos (higienizar), fazer curativos, ver como estão passando (se estão “em crise"), vigiar, cuidar para que não façam nada de errado, para que não fujam, examinar o corpo (medir a pressão, tirar a temperatura, auscultar).

É possível perceber aqui contrastes que indicam diferentes percepções do que sejam as tarefas mais importantes a serem desenvolvidas junto aos pacientes. Embora na abordagem comunitária da transformação essas discrepâncias tendam a ser negadas, elas continuam existindo no âmbito das representações dos atores, e podem ser explicitadas de forma bem aparente em momentos de crise institucional. 


\section{Ideário do processo de mudança}

Procurarei aqui delinear e analisar algo que poderíamos chamar de "ideário" do processo de mudança - conjunto de princípios, objetivos e valores que presidem tal processo. Com este objetivo, reunimos os temas mais recorrentes no discurso dos entrevistados - agentes sociais que sugerem e executam as propostas de transformação do hospital —, lançando mão, também, de textos e programas relacionados com o projeto de mudança desenvolvidos na instituição.

Em um primeiro momento, aparece como bastante consensual entre os diversos entrevistados que a CJM é um "lugar de marginalização" para onde a sociedade envia pessoas, segregando-as de seu convívio, muito mais por julgá-las indesejáveis do que para tratá-las, recuperando-as para o retorno à sociedade de onde vieram.

Em uma segunda instância, o hospital é encarado como o grande responsável pelo estado de degradação em que os internos se encontram: em função do isolamento e privações que impõe a seus abrigados, ele dilui suas identidades e os "cronifica" como doentes. A situação de miserabilidade física e mental dos internos é então atribuída ao hospital em si, muito mais que à evolução de qualquer tipo de "doença mental" que porventura apresentassem quando foram internados.

Uma terceira noção, em grande parte decorrente das duas anteriores, apresenta a CJM como um espaço tecnicamente anacrônico, eticamente injusto e politicamente autoritário e antidemocrático, algo que o processo de mudança deve, em última análise, fazer desaparecer.

A negação do hospital-colônia como espaço terapêutico e a denúncia de suas finalidades implícitas de marginalizar e seqüestrar a cidadania de pessoas consideradas indesejáveis ao convívio social, constituíram, portanto, temas centrais no ideário de mudança. Essas noções conduziram ao estabelecimento de um amplo projeto de ressocialização que visava, em última análise, fazer retornar à sociedade aqueles que ela havia segregado no passado. Levaram também ao fechamento das portas do hospital para novas internações, decretando desta forma seu fim como recurso de assistência ou custódia.

Cabe aqui analisar alguns pressupostos subjacentes às posições assumidas pelos técnicos e aos programas implantados, pressupostos estes que foram adotados a priori, e que, apesar de sua grande importância como fundamentos teóricos nos quais se respaldava o processo de mudança, acredito não terem sido suficientemente problematizados. 
Em primeiro lugar, vejamos a idéia de que os "crônicos" sejam sempre produzidos pelo hospital ou por tratamento inadequado: decretando o fim dos estabelecimentos para crônicos, estes deixariam de existir. Esta idéia (e a do processo de mudança), assumida no início dos anos 80 de forma mais ou menos dogmática, foi posteriormente relativizada. Neste sentido, Delgado, um dos mentores teóricos do processo em estudo, reavalia, em 1991, como "temerária" a afirmação feita por ele em artigo publicado em 1982, no qual sustentava a determinação institucional da "cronificação" como processo universal e inexorável para os asilados. ${ }^{21}$

Esse pressuposto, que se origina na tese mais geral de uma construção social da doença mental, oferece algumas dificuldades quando aplicado à questão específica dos doentes crônicos, sobretudo para os tipos de doentes encontrados em estabelecimentos como a CJM. A partir de um exame dos pacientes dessa instituição, de seus prontuários e diagnósticos, é possível observar que muitos deles apresentam doenças como oligofrenias, demências, lesões cerebrais e outras que, não sendo passíveis de reversão, quaisquer que sejam os tratamentos empregados, tendem inexoravelmente à "cronificação", quer estejam internados ou não.

$\mathrm{Na}$ verdade, existem doenças que evoluem para a "cronicidade" independentemente de qualquer tratamento ou hospital, e não parece provável que a simples extinção dos hospitais para crônicos levaria a que estes não mais surgissem. Quanto a este tópico, tornamos nossa a crítica de Bachrach que assim coloca a questão:

"O movimento de desinstitucionalização pode evitar as funções de custódia e asilo, mas deve ainda reconhecer que estas têm sido funções do hospital psiquiátrico e que a demanda por elas não irá simplesmente desaparecer com o desmantelamento das instituições de custódia. Este reconhecimento poderá trazer a mudança no planejamento e na ação."22

Em segundo lugar, consideremos a idéia de que impedir a entrada de novos pacientes no hospital de crônicos, visando em última análise à sua extinção, poderia levar a que eles conseguissem algum lugar mais adequado na sociedade extramuros.

21 P. G. G. Delgado, “Determinantes Institucionais de...”, op. cit., p. 120.

22 L. L. Bachrach, "Deinstitutionalization: An Analytical Review and Sociological Perspective", Series $D, \mathrm{n}^{\circ} 4$, Rockville, Maryland, National Institute of Mental Health, 1976. 
Um fato que pôde ser observado após o fechamento das portas do hospital-colônia para novas admissões foi que os pacientes crônicos passaram a se acumular em hospitais de curta permanência, ou de "agudos".

O projeto do Hospital Jurandyr Manfredini, criado em 1982, consubstanciava-se na crença de que pacientes crônicos se formam por causa de tratamento inadequado, e previa fornecer atendimento de alta qualidade de modo a não os gerar. Entretanto, apesar de todas as normas visando impedir internações longas, após dois anos de funcionamento cerca de um sexto dos leitos estava ocupado por pacientes que passaram a residir no hospital mais por não terem para onde ir se recebessem alta do que pela necessidade de tratamento.

Por último, cabe comentar o tema básico da ressocialização: de que é possível levar a sociedade a reintegrar aqueles a quem baniu, prescindindo desse tipo de espaço de segregação. Aqui, a dificuldade fundamental está em que muito pouco pode ser feito no âmbito do hospital, pelos técnicos, para a reintegração do paciente; a questão, eminentemente social, envolve, sobretudo, a disposição de suas famílias para recebê-los de volta.

Alguns internos já haviam perdido o contato com suas famílias mesmo à época de sua internação, tendo sido trazidos ao hospital pela polícia que os recolheu na via pública como indigentes. Em outros casos, o longo período de internação ocasionou o rompimento dos laços familiares.

De qualquer modo, os internos da CJM provêm de segmentos socioeconômicos muito baixos e suas famílias não dispõem de recursos para abrigar um membro economicamente improdutivo, sobretudo se este requer atenções especiais como estar sempre acompanhado e precisar de assistência médica periódica.

Por outro lado, a noção bastante difundida de que o hospital é o lugar mais adequado para se tentar a "cura", ou mesmo para a simples permanência dos doentes, cria uma resistência inercial à reintegração dos internos à sociedade.

Uma característica bastante comum nos depoimentos dos técnicos protagonistas do processo de transformação é sua autodefinição como profissionais "de esquerda" na área de saúde mental, em confronto com posições de outros que são vistos como "de direita": "[...] porque nós estávamos lutando contra todas as forças, as correntes psiquiátricas que ainda hoje têm peso muito grande, as correntes que representam a direita, isso eu não tenho a menor dúvida em dizer[...]". ${ }^{23}$

Recorrendo ao discurso de um de nossos entrevistados, é possível sintetizar a posição de "esquerda" como sendo a que questiona e contesta o 
papel encobridor de conflitos sociais que a psiquiatria tem tradicionalmente representado. Nesta concepção, o psiquiatra aparece como um agente social que justifica, com a chancela da ciência médica, a segregação de indivíduos previamente marginalizados pelo sistema. Assim, o psiquiatra, com seus "diagnósticos" e "tratamentos", legitimaria a marginalidade, oferecendo um respaldo "científico" para um mecanismo de exclusão social em que a doença não seria a causa primeira. A posição dos profissionais de "direita" seria aquela que, sem questionar, endossa esse papel encobridor. Esse confronto de posições e abordagens radicalizadas parece ser típico das etapas iniciais do processo de desinstitucionalização da assistência psiquiátrica, como assinala Bachrach em sua análise da questão:

"Em resumo, o movimento de desinstitucionalização tem sido, desde seu início, caracterizado por uma polarização de atitudes - um processo que não é raro em circunstâncias onde a mudança social envolve questões com matizes emocionais. Uma descrição do processo de polarização pode ser encontrada na literatura sociológica: 'Necessariamente, as questões públicas tendem a ser formuladas em termos dicotômicos, como Guerra ou Paz, Protecionismo ou Livre Comércio. [...] Isto não significa que cada problema possua apenas duas facetas, mas simplesmente que a ação pública possa ser melhor mobilizada; um denominador pode ser mais facilmente atingido, quando existem apenas dois lados. A fórmula mais comum é a colocação 'contra ou a favor'. '"24

Essa temática se atualiza diante do Projeto de Lei $n^{\circ} 3657 / 89$ do deputado Paulo Delgado (PT-MG), que propõe a extinção gradual dos asilos manicomiais públicos, dividindo as opiniões.

Conforme já assinalamos, a experiência da psiquiatria democrática italiana, ao ser considerada como principal modelo inspirador do processo de mudança na Colônia Juliano Moreira, traz implicações que merecem atenção.

Para os pesquisadores que produziram análises sistemáticas sobre a experiência italiana, esta tem especificidades tais que contra-indicam a reprodução simples do modelo, como aponta Ramon:

"A experiência italiana não pode ser imitada porque tem suas raizes na especificidade do contexto social italiano. Realmente, um dos pré-requisitos para obter sucesso em um empreendimento de mudança social é um alto grau de capacidade de tornar-se parte da cultura vernacular. $" 25$

23 Entrevista com um psiquiatra, diretor de hospital, em 20/3/1984.

24 K. Davis, Human Society, Nova Iorque, The MacMillan Company, 1949, apud L. Bachrach, "Deinstitutionalization: An Analytical...", op. cit., p. 7.

25 Cf. S. Ramon, "Psichiatria Democrática: A Case Study of an Italian Community Mental Health 
Uma outra análise considera que a reforma empreendida pela "psiquiatria democrática" apenas foi possível porque ocorreu sob a égide de um governo especial e graças à colaboração entre democrata-cristãos e comunistas. A amplitude de fatores sociais envolvidos torna aquela experiência única e sem paralelo no mundo ocidental. ${ }^{26}$

De fato, a ausência/presença de fatores que condicionam a interface entre sociedade e psiquiatria apontam para importantes diferenças entre a experiência italiana e esta que analisamos. Naquele caso, a aliança entre forças progressistas nos setores científico e sociopolítico propiciou um respaldo expressivo para a mudança no âmbito do governo, que não se observou no caso brasileiro.

Neste, a democratização do hospital constituiu, desde o início, um dos objetivos centrais do processo de mudança. Entretanto, uma certa relativização se faz necessária aqui. Cabe apontar que a democratização das instâncias de poder no hospital, um projeto essencialmente político, tinha importância bem maior para os técnicos - que o idealizaram - que para os funcionários e pacientes. Para compreender essa questão é preciso atentar para um aspecto importante; o fato de que existem diferentes formas de participar profissionalmente da instituição: trabalhar no hospital como técnico difere em alguns aspectos da experiência de participar como funcionário. Ao comparar a inserção profissional de enfermeiros e médicos do hospital psiquiátrico, Majastre, baseando-se em Goffman, observa que: "eles [enfermeiros] têm empregos, não carreiras. Já os médicos têm carreira, fazem carreira, e [...] esta distinção é capital." 27

Assim, democratizar, significando "a distribuição equilibrada e consensual do poder dentro da instituição", constituía um processo que envolvia muito mais diretamente os profissionais de nível superior, notadamente os médicos, para quem era possível "fazer carreira", que funcionários como os auxiliares e atendentes de enfermagem que lá apenas tinham "um emprego".

Durante cerca de seis décadas a CJM funcionou segundo um pensamento psiquiátrico "clássico", que a considerava como um espaço necessário para tratar ou custodiar pessoas que, em conseqüência de sua enfermidade

Service", International Journal of Health Services, vol. 13, $\mathrm{n}^{\circ} 2,1983, \mathrm{p} .307$.

26 Cf. P. Crepet e G. De Plato, "Psychiatry without Asylums: Origins and Prospects in Italy", International Journal of Health Services, vol. 13, $\mathrm{n}^{\circ} 1,1983, \mathrm{p} .119$.

27 J. O. Majastre, L'Introduction du Changement..., op. cit., p. 31. 
mental, não poderiam viver fora dele. Recebia então pacientes "selecionados" de outros hospitais psiquiátricos, enviados por serem considerados "incuráveis", "crônicos" ou por necessitarem de "hospitalização de longa duração" - um eufemismo que significava, na realidade, "pelo resto da vida". Esse funcionamento correspondia a uma certa matriz teórica, a uma atitude dos técnicos que geriam o hospital e que o consideravam como o lugar mais adequado para abrigar pessoas que não lograram encontrar outro espaço na sociedade, ou por deficiência psíquica e/ou por falta de suporte socio-familiar. Em resumo, essa atitude significava legitimar o asilo como o lugar inevitável dos pacientes "crônicos".

A postura de nossos entrevistados - orientadores da mudança - origina-se de uma visão frontalmente oposta à anterior, muito inspirada no pensamento basagliano. Segundo eles, a condição de crônico é gerada muito mais pelo próprio asilo e pela origem socioeconômica do interno que pelas doenças. Esta lógica decreta a inadequação e a extinção do asilo.

As divergências entre essas duas perspectivas podem ser melhor percebidas no cotejamento de duas grandes correntes do pensamento psiquiátrico no que tange à consideração das origens das doenças mentais. A primeira localiza a base dos distúrbios nos próprios indivíduos que os apresentam: a segunda situa a fonte dos problemas no ambiente social e nas relações mantidas entre este e os indivíduos. Hersch, estudando as bases ideológicas do movimento de desinstitucionalização da assistência psiquiátrica, aponta correlações entre "os tempos" e as tendências do pensamento psiquiátrico. Assim, em um período de conservadorismo sociopolítico, a inclinação preponderante seria de situar no indivíduo a origem dos problemas, enquanto em um período de reformismo seria mais freqüente prevalecer a vocação para procurar no meio social a origem dos distúrbios. ${ }^{28}$

Coincidentemente com o que afirma Hersch, o processo de mudança que analisei - que tende a atribuir ao meio mais que ao indivíduo a causa da cronicidade - se instaura no início dos anos 80 . período considerado como o da "abertura", após duas décadas de conservadorismo político consoante com a ditadura militar.

Conquanto o projeto de democratização tenha sido assumido mais significativamente pelos técnicos que pelos pacientes, ele teve grande importân-

28 Cf. C. Hersch, "Social History. Mental Health and Community Control", American Psychologist, $\mathrm{n}^{\circ} 27$, agosto de 1972. pp. 749-54. 
cia como catalisador do processo de mudança, fornecendo motivação e coesão em torno de um objetivo comum que dificilmente seria atingido de outra forma. ${ }^{29}$

Da mesma maneira, é possível observar que no caso analisado alguns dos programas centrais, tanto para o processo de desospitalização como para o de ressocialização dos internos, não lograram na prática efetivar suas metas ${ }^{30}$ Entretanto, a partir dessa constatação, considerá-los apenas como lip service corresponderia a uma visão reducionista que deixaria fora do foco de análise a importância simbólica que desempenharam, mobilizando técnicos, funcionários e pacientes na direção de um ideal comum de mudança, contribuindo para vencer a inércia institucional.

Como assinala um pesquisador ao analisar o processo americano, soluções demasiado singelas podem ser apresentadas para questões complexas. muito mais como estratégia de mobilização política, no sentido de "bandeiras de luta" ou "palavras de ordem", do que como respostas tecnicamente efetivas:

"É da natureza do processo político promover a supersimplificação de questões complexas de forma que uma solução única possa ser advogada para superar a inércia que inibe mudanças maiores na política ou prática governamentais. A desinstitucionalização foi a solução política proposta nos anos 60 como resposta a reivindicações profissionais por melhorias substanciais na assistência prestada por hospitais públicos e pela criaçâo de um sistema assistencial de saúde mental baseado na comunidade. ${ }^{* 31}$

\section{Apropriação do pensamento basagliano}

Os técnicos demonstram em seus depoimentos acreditar que, em sua maioria, os determinantes das internações na CJM são de ordem social e econômica, mais do que fruto de doenças no sentido estrito. Esta abordagem.

29 Para uma análise do projeto de democratização do hospital. considerado como um "mito institucional", ver M. S. Andrade, Democratização no Hospital Psiquiátrico: Um Estudo da Colônia Juliano Moreira nos Anos Oitenta, Tese de Mestrado em Saúde Coletiva, Instituto de Medicina Social/UERJ, 1992.

30 Ver, neste sentido, M. Lougon, M. S. Andrade e R. Catharino. Avaliação de um Programa de Ressocialização para Crônicos: A Etapa I, Rio de Janeiro, Colônia Juliano Moreira, 1985. mimeo.

31 J. F. Borus, "Deinstitutionalization of the Chronically Mentally III", The New England Journal of Medicine, agosto de 1981, p. 339. 
como já sugeri, se inspira nas formulações da psiquiatria democrática italiana. Caberia alguns comentários sobre o modelo teórico aportado por esta corrente, assim como sobre as características de sua apropriação em nosso meio.

Castel, ao abordar as transformações do campo médico-psicológico atual, que considera não mais dominado pela psiquiatria clássica e pela psicanálise, analisa sociologicamente o novo modelo no qual acredito possa se incluir a proposta da psiquiatria democrática italiana:

" - a dissolução da vontade de se encarregar totalmente da tradição da medicina mental que, autorizando a dissociação do diagnóstico e do tratamento, tende a substituir a prática de tratamento por uma prática de expertise generalizada, à base de estratégias inéditas de gestão das populações. ${ }^{32}$

A psiquiatria democrática italiana, conforme comenta Pitta-Hoisel, "tem um caráter abertamente político, que a distingue nitidamente dos outros movimentos europeus". ${ }^{33}$ Neste sentido, acredito que ela tenha privilegiado uma estratégia de intervenção política na instituição psiquiátrica, e sobretudo em suas relações com a sociedade, vendo na desinstitucionalização uma perspectiva de recuperação do legado de seqüelas cívicas produzido pelo modelo manicomial.

A ênfase na proteção dos direitos de cidadania dos "psiquiatrizados" foi concretizada, na Itália, por meio de uma mudança no código de regulamentação jurídica daqueles direitos, a Lei ${ }^{\circ} 180$, de 1978. Esta se afigura como uma das maiores conquistas no sentido da desconstrução do asilo como instituição negada e nos revela uma face mais política que clínica do movimento.

Ao privilegiar a abordagem política do problema das internações psiquiátricas a corrente italiana deslocou o foco de atenção antes centrado na doença mental e seu tratamento. Assim, negou a necessidade de construção de um modelo teórico-explicativo da doença (diagnóstico, prognóstico, terapêutica) no sentido em que o fizeram, por exemplo, as escolas de tradição biológica e psicanalítica.

Este enfoque, que descarta a importância de uma teoria sobre a doença aparece, por exemplo, no seguinte comentário de Basaglia:

32 R. Castel, A Gestāo dos Riscos.... op. cit.. p. 68.

33 A. M. Pitta-Hoisel. Sobre uma Política.... op. cit..p. 25. 
" [...] uma vez que a doença não é o elemento determinante daquela condição do doente mental revelada em nossos asilos de alienados, devemos examinar agora os elementos que, por estranhos que sejam a esta condição, nela têm um papel de grande importância. .34

Tratando desses elementos, ele afirma que a exclusão que a saúde mental faz se relaciona mais à falta de poder contratual (socioeconômico) do doente do que à doença em si. E exemplifica dizendo que um esquizofrênico rico internado em uma clínica privada não terá o mesmo diagnóstico que um esquizofrênico pobre internado em um hospital psiquiátrico público. Referese aos efeitos "deshistorizantes", destrutivos e institucionalizados presentes no segundo caso.

Ao caracterizar a inutilidade e nocividade da nosologia psiquiátrica, Basaglia considera que ela apenas substitui a perda de identidade do doente. acarretada pela psicose, por um rótulo ou uma identidade deteriorada correspondente ao diagnóstico psiquiátrico.

Mais recentemente. essa mesma postura se verifica em Franco Rotelli. que afirma:

"Pouco se pode fazer com a doença como a queria o modelo clínico ou com o sintoma e o conflito como o queria o modelo psicológico, porque mudaram o objeto, o paradigma e, com eles, os sensatos programas.

À doença (diagnóstico, prognóstico, terapia) e sua consubstancial relação de causa e efeito correspondiam instituiçōes coerentes."35

O mesmo autor segue observando que a doença, objeto de tratamento e investigação da psiquiatria tradicional, é substituída, na verdadeira desinstitucionalização, pela “"existência-sofrimento' do paciente em sua relação com o corpo social". 36

A psiquiatria democrática italiana assemelha-se aqui ao movimento antipsiquiátrico de Laing e Cooper, que também criticavam a tendência da psiquiatria clínica de tradição acadêmica por ter construído uma psicopatologia e nosologia psiquiátricas mais preocupadas em analisar os sintomas e a doença do que a pessoa do doente.

Entretanto, a antipsiquiatria inglesa construiu um modelo teórico explicativo da doença mental, tendo a esquizofrenia como paradigma, e de sua

34 F. Basaglia, L'Institution en Négation. Paris. Seuil. 1970, p. 112.

35 F. Rotteli, "A Instituiçāo Inventada", in Fernanda Nicácio, org., Desinstitucionalização, São Paulo, Hucitec, 1990, p. 91.

36 Ibidem. 
abordagem terapêutica. Acredito, neste sentido, que a explicitação de um modelo teórico seja conveniente, pois, como há muito tempo nos mostrou Bachelard, a noção de corte epistemológico que instaura um novo saber rompendo com o pré-saber supõe a emergência de um quadro teórico mais heurístico com maior alcance e poder explicativo.

A perspectiva política que propõe a mudança de objeto de doença mental para "existência-sofrimento" do paciente em sua relação com o corpo social não parece oferecer um desvendamento maior para as questões anteriormente propostas tendo a doença como objeto, simplesmente por desqualificá-las.

Conquanto seja inegável o avanço trazido pelo aporte político da psiquiatria democrática italiana, consubstanciado nas mudanças introduzidas pelo otimismo da prática, caberia formular novas propostas no âmbito do pessimismo da razão. Ou seja, produzir um modelo teórico original — não um mosaico eclético - explicativo da doença (ou do objeto que a substitui) e de sua terapêutica (ou da abordagem que a substitui).

A atitude de consagrar um certo desprezo por modelos teóricos e questões deles emanadas, como característica da psiquiatria democrática italiana, foi assinalada por Ramon:

“A postura antiteórica assumida pela maioria dos trabalhadores [de saúde mental da psiquiatria democrática italiana] [...] envolve uma negação do que tem sido visto como 'tipico' de instituições acadêmicas e médicas. Esta postura contradiz crenças essenciais da psiquiatria democrática sobre a necessidade de compreender a interface entre sociedade e psiquiatria". 37

Quanto à apropriação do pensamento basagliano feita em nosso meio. acredito que uma parte dele foi mais absorvida e utilizada instrumentalmente por profissionais de saúde mental engajados na transformação de hospitais psiquiátricos públicos. Trata-se de um approach político das formulações de uma estratégia de desconstrução do asilo com todas as suas conquistas para o direito de cidadania dos internos. A parte desse pensamento que propõe o abandono da noção de doença mental e seu tratamento, oriunda do modelo clínico de tradição acadêmica legitimado nas faculdades de medicina, não foi objeto de uma abordagem teórica cuidadosa, sendo menos absorvida que aquela perspectiva e estratégia políticas.

37 S. Ramon, "Psichiatria Democrática...", op. cit.. p. 322. 
Assim, as práticas psiquiátricas desenvolvidas sob a inspiração do modelo basagliano no Rio de Janeiro, nos anos 80, não reproduzem aquela fração do modelo que abandona a noção clínica da doença mental e seu tratamento. Evidência dessa atitude pode ser verificada no caso do Hospital Jurandyr Manfredini, concebido e inaugurado, em 1982, como alternativa ao hospital psiquiátrico convencional, em meio ao processo de mudança institucional na Colônia Juliano Moreira. fortemente inspirado na psiquiatria democrática italiana.

Um dos protagonistas daquele processo assim analisa, criticamente, o modelo teórico efetivamente acionado em suas práticas terapêuticas:

“As condições de reprodutibilidade do ethos asilar no Hospital Jurandyr Manfredini são notórias. [...] 'O Manfredini é um hospital clássico como um outro qualquer', costumam dizer seus médicos e psicólogos, onde o 'clássico' remete diretamente à psiquiatria biológica haurida da matriz kraepeliniana." 38

\section{Alcance e limites do processo de mudança: considerações críticas}

Tratarei agora de sintetizar e relacionar entre si alguns tópicos expostos ao longo do texto, apontando para questões que me parecem relevantes para a compreensão do contexto institucional como uma totalidade.

Uma das principais limitações do processo de mudança prende-se ao fato de que o "modelo de exclusão social" se localiza dispersamente nos domínios do social, de cada cidadão, de cada família que rejeita o desviante, e não apenas dentro do asilo. O processo de exclusão é, portanto, anterior e exterior aos muros do asilo, que apenas representa um ponto final na trajetória ou "carreira" do desviante. O alienista tem, com seu mandato, delegação de poder e autoridade para legitimar a exclusão e exercer a custódia ou "tratamento" dos excluídos; é, entretanto, impotente se utiliza apenas o instrumental teórico-clínico de seu ofício de psiquiatra para mudar o modelo que se origina e opera na sociedade exterior ao asilo.

Para resolver esse impasse, a psiquiatria democrática italiana, desprivilegiando o modelo clínico, propõe a estratégia política de intervenção no social, como afirma Basaglia: "A solução técnico-psiquiátrica que preconiza 
a reabilitação do doente mental é simultânea à sua exclusão social [...] que é um problema tecnicamente insolúvel, tratando-se de uma questão política e social". 39

Um ponto de partida para superar as ambigüidades que têm, historicamente, marcado a CJM, seria talvez a explicitação de suas finalidades efetivas, ou atividades-fim, do tipo de clientela que recebe e de suas relações com a estrutura social mais ampla na qual se insere.

Em primeiro lugar, cabe tentar definir a composição básica da clientela que era encaminhada à CJM e ainda o é para instituições similares. Para tal, podemos recorrer a Diva Moreira, que formula a questão de forma bastante abrangente e em sintonia com o pensamento dos técnicos que entrevistei, e que acredito esteja aí sintetizado:

"A instituição psiquiátrica desempenha função custodial para indivíduos que, marcados por alguma forma de incapacitação - como idade (os muitos jovens ou velhos), doença. defíciência mental, defeito físico, ou de inadaptação aos sistemas de produção e consumo (mendigos e vagabundos, incluindo em grande parte também os primeiros) - , foram sancionados com a invalidação social e, conseqüentemente, com a rejeição por parte da família." 40

A demanda é, portanto, por serviços de natureza antes custodial que terapêutica, originada na rejeição da comunidade pelos seus membros deslocados das relações de produção e consumo, e/ou que apresentem hábitos considerados como anti-sociais.

Diante dessa evidência, estudiosos americanos do movimento de desinstitucionalização, com a tendência que lhes é peculiar de operacionalizar o problema, classificando de forma precisa a clientela que constitui a demanda, colocam as seguintes questões: precisamente quais pacientes devem ser desinstitucionalizados? Estamos nos referindo a todos os internos em asilos psiquiátricos? Ou àqueles que por características demográficas ou de seu diagnóstico devem receber tratamento na comunidade? Trata-se daqueles que foram inadequadamente hospitalizados por não terem outro lugar para ir?

Brody, estudando causas de internações psiquiátricas no Rio de Janeiro, destaca a pobreza como fator relevante:

"O denominador comum é a incapacidade da família de cuidar de um membro não produtivo, que pode ser associada com um ressentimento dirigido a este fardo adicional.

39 F. Basaglia apud D. P. D. Barros, A Desinstitucionalização Italiana: A Experiência de Trieste, Tese de Mestrado em Ciências Sociais, PUC/SP. 1990, p. 48.

40 D. Moreira, Psiquiatria: Controle e Repressão Social. Belo Horizonte, Vozes, 1983. 
A ameaça real, para a qual o cuidado psiquiátrico é a cura sugerida, é a sobrevivência econômica da unidade familiar." 41

Efetivamente, a clientela que busca os serviços da CJM e estabelecimentos congêneres tem sua extração social básica no lúmpen, e sua demanda primeira é por abrigo, alimentação, vestes e custódia, mais do que por tratamento psiquiátrico propriamente dito.

Um risco imediato do processo de desinstitucionalização no caso estudado, é o de extinguir o espaço asilar sem ter antes criado alternativas a ele. Em uma reflexão sobre a experiência americana do processo de desinstitucionalização ocorrido entre 1955-75, Bassouk observa criticamente que:

"A população de pacientes que residiam em grandes hospitais psiquiátricos foi reduzida de dois terços num período de vinte anos, mas pacientes crônicos estão sendo lançados em comunidades hostis e condenados a uma existência solitária sem tratamento adequado. $" 42$

De forma análoga, podemos considerar que o fechamento das portas de instituições como a CJM para novas internações, acarretando a cessação da oferta de suporte psiquiátrico para crônicos, cria uma lacuna que não parece ter sido preenchida. A questão daí decorrente pode ser assim formulada: para onde vão agora os pacientes que eram antes encaminhados a essas instituições?

Algumas evidências sugerem que alguns estejam longamente internados em hospitais de "agudos", próprios para curta permanência; outros, em estabelecimentos policiais; outros, simplesmente aumentando a assim chamada "população de rua".

A situação criada pode ser vista como um problema de demanda reprimida, em que a reação da clientela é "surda" ou inaparente, pois os segmentos da população afetados - que fazem parte do mais baixo escalão socioeconômico — não dispõem de organização ou canais que possibilitem sua manifestação a esse respeito.

Curiosamente, a história mostra-se cíclica e ocorre como que um retorno não-planejado ao nosso período pré-asilar quando, pela inexistência de hospícios, cabia à polícia lidar com essa clientela e dar-lhe um destino. Se o psiquiatra se recusa a continuar a exercer seu tradicional papel de "polícia

41 E. Brody, The Lost Ones: Social Forces and Mental Illness in Rio de Janeiro, Nova Iorque, International University Press, 1973.

42 E. L. Bassuk e S. Gerson, "Deinstitutionalization and Menthal...”, op. cit., p. 46. 
das famílias", a polícia comum pode substituí-lo na tarefa de cuidar dos excluídos.

Caracteriza-se assim um sério impasse: por um lado, manter a atual situação de demandả reprimida e desassistência da clientela, conservando fechadas as portas da CJM, o que significa também decretar o seu fim a curto ou médio prazo. Por outro lado, abrir as portas para novas internações pode significar a manutenção de um modelo asilar obsoleto e rejeitado por todos.

A inexistência de estabelecimentos especializados (albergues, asilos para velhos, abrigos para deficientes físicos etc.) dirige para o hospital de crônicos esta demanda por custódia e hotelaria, "psiquiatrizando-a". Enquanto essas instituições não forem criadas, é improvável que ocorram transformações substanciais nos hospitais existentes.

A utilização do hospital por segmentos da população de baixa renda, os "despossuídos", apresenta-se de forma bastante crua não só com o fenômeno de invasão de terras da instituição por pessoas que apenas desejam um espaço para construir seus barracos, mas também com a ocupação de hospitais desativados. Aqui, a relação do hospital com a estrutura social mais ampla onde se insere apresenta-o como um espaço de fronteiras flexíveis diante das pressões do processo de urbanização.

Da mesma forma como no início do século, quando as necessidades geradas pelo processo de urbanização do Rio de Janeiro causaram a transferência da Colônia para Jacarepaguá nos anos 20 , novamente as mesmas exigências de expansão urbana voltam a "atropelar" a instituição nos anos 80.

A desinstitucionalização, conquanto um processo inexorável e necessário, implica uma contrapartida de investimentos em outros recursos e modelos de assistência. O simples fechamento das portas de instituições como a CJM não oferece nenhuma alternativa para a clientela que necessita dos assim chamados "cuidados de longa duração" ou mais simplesmente, custódia. Tomando um exemplo bastante conhecido, não considerando as questões conceituais envolvidas no processo de desinstitucionalização americano, nos EUA o fechamento dos State Hospitals se fez acompanhar da criação de Centros Comunitários de Saúde Mental, pensões protegidas, abrigos geriátricos etc. No nosso caso, em que pese algumas experiências pioneiras e isoladas, não parece haver, de modo mais sistemático, um planejamento efetivo para a implantação destes ou outros recursos alternativos na comunidade. 


\section{RESUMO \\ Desinstitucionalização da Assistência Psiquiátrica: Uma Perspectiva Crítica}

$\mathrm{O}$ artigo tematiza a experiência de desinstitucionalização da assistência psiquiátrica vigente em hospitais públicos do Rio de Janeiro nos anos 80 , a partir do processo de mudança institucional ocorrido na Colônia Juliano Moreira, tendo por base a crítica ao modelo asilar típico e a exclusão social nele implicada. Analisa a estratégia e as atitudes de mudança presentes no caso estudado, que objetivavam a humanização e democratização do hospital. Decorre sobre o ideário dos agentes institucionais que propõem a transformação e examina a apropriação feita em nosso meio de formulações da psiquiatria democrática italiana. Finalmente, aponta para o alcance e impasses do caso abordado em face das características socioeconômicas do País que requer cuidados críticos na formulação de uma política de desinstitucionalização.

\section{ABSTRACT \\ De-institutionalization of Psychiatric Care: A Critical Perspective}

The article addresses the de-institutionalization of psychiatric care in Rio de Janeiro's public hospitals during the 1980s. It takes as its case study the process of institutional change that took place at the Colônia Juliano Moreira psychiatric facility, prompted by criticisms of the typical asylum model and the social exclusion implied in it. The article analyzes the strategy of, and attitudes towards, this change, which sought to humanize and democratize the hospital. It describes the set of ideas displayed by the institutional agents proposing the transformation and examines how formulation have been adopted from Italy's democratic psychiatry. Lastly, the article points to the scope and impasses of the case in question from the perspective of Brazil's socioeconomic characteristics, which make necessary utmost caution when devising a de-institutionalization policy. 


\section{RESUME}

\section{La Desinstitutionnalisation de L'assistance Psychiatrique: une Perspective Critique}

Cet article fait un relevé des thèmes ayant trait à l'expérience de désinstitutionnalisation de l'assistance psychiatrique réalisée dans les hôpitaux publics de Rio de Janeiro au cours des années 80 . Cette expérience a eu comme point de départ le processus de changement institutionnel survenu à la Colônia Juliano Moreira à partir des critiques faites au modèle asilaire et à l'exclusion sociale qu'il engendre. L'auteur analyse la stratégie et les attitudes novatrices observées dans le cas en étude. Elles avaient pour but de permettre l'humanisation et la démocratisation de l'hôpital. Il décrit les idéaux des agents instituionnels qui furent à l'origines des transformations proposées et étudie la façon dont certains postulats de la psychiatrie démocratique italienne furent appropriés parmi nous. Il signale en conclusion la portée et les impasses du cas analysé face aux caractéristiques socio-économiques du Brésil qui requièrent notamment précautions et esprit critique lors de la formulation de toute politique visant à la désinstitutionnalisation. 